\title{
Pre- and Postsynaptic Determinants of EPSC Waveform at Cerebellar Climbing Fiber and Parallel Fiber to Purkinje Cell Synapses
}

\author{
Michiko Takahashi, Yury Kovalchuk, ${ }^{\mathrm{a}}$ and David Attwell \\ Department of Physiology, University College London, London, WC1E 6BT, England
}

\begin{abstract}
Excitatory postsynaptic currents (EPSCs) at the parallel fiber and climbing fiber to Purkinje cell synapses were studied by whole-cell clamping Purkinje cells in cerebellar slices. Reducing glutamate release with adenosine or GABA decreased the amplitude of the EPSCs, with a larger suppression being produced at the parallel fiber synapse. Reducing glutamate release also speeded the decay of the EPSCs, and this effect was not a series resistance artefact since postsynaptic reduction of the current with CNQX did not speed the EPSC decay. Blocking glutamate uptake slowed the decay of the EPSCs. At the climbing fiber synapse, adenosine had little suppressive effect on the smaller EPSC evoked by the second of a pair of stimuli. Blocking desensitization of postsynaptic AMPA receptors prolonged the EPSC decay, preferentially increased the size of the second EPSC, and resulted in adenosine having a similar suppressive effect on the first and second EPSC. These data suggest that, at these synapses, the fall of glutamate concentration in the synaptic cleft overlaps with the decay of the EPSC, and that the EPSC size and duration are controlled by the amount of glutamate released, the rate of glutamate uptake, and desensitization.
\end{abstract}

[Key words: glutamate, EPSC, kinetics, release, uptake, desensitization]

The non-NMDA component of the postsynaptic current at glutamatergic synapses is shaped by presynaptic factors (the amount of glutamate released), by postsynaptic factors (receptor properties), and by the rate of glutamate removal from the synaptic cleft by diffusion and uptake. At cerebellar mossy fiber to granule cell synapses and hippocampal Schaffer collateral to pyramidal cell synapses inhibiting glutamate uptake does not affect the EPSC decay time course (Hestrin et al., 1990; Isaacson and Nicoll, 1993; Sarantis et al., 1993), which may be dominated by the time course of channel deactivation following rapid diffusion of glutamate out of the synaptic cleft (Colquhoun et al., 1992; Silver et al., 1992, 1994). However, at a cochlear nucleus synapse, the synaptic current decay is dominated by desensitization

\footnotetext{
Received Jan. 30, 1995; revised Mar. 29, 1995; accepted Mar. 30, 1995

This work was supported by the Wellcome Trust and M.R.C. We thank Brian Billups for testing the effect of diazoxide on glutamate uptake, Peter Mobbs for computing advice, and Alisdair Gibb and Angus Silver for criticism of the article.

Correspondence should be addressed to David Altwell, Deparment of Physiology, University College London, Gower Street, London, WC1E 6BT, England.

"Permanent address: Bogomoletz Institutc of Physiology, Kiev, Ukraine.

Copyright $(1995$ Society for Neuroscience $0270-6474 / 95 / 155693-10 \$ 05.00 / 0$
}

of the postsynaptic receptors (Trussell et al., 1993), suggesting a more prolonged presence of glutamate in the synaptic cleft.

Here we investigate the factors determining the synaptic current waveform at the two excitatory synapses onto cerebellar Purkinje cells from climbing fibers and parallel fibers. Understanding these synapses is important for understanding the modulation of motor output by the cerebellum, and the plasticity of the parallel fiber to Purkinje cell synapse produced by coincident activation of the parallel and climbing fibers (Linden and Connor, 1993). Barbour et al. (1994) have reported that blocking glutamate uptake or AMPA receptor desensitization prolongs the synaptic current at these synapses, results which we confirm here. However, prolongation of the EPSC by blocking uptake does not prove that uptake sets the EPSC decay rate when it is not blocked, and drugs used to block desensitization also increase receptor affinity which could prolong the EPSC. In this study, therefore, we investigate further the contribution of glutamate removal and desensitization to shaping the EPSC by using adenosine and GABA as tools to vary the amount of glutamate released presynaptically.

Adenosine acts on presynaptic $A_{1}$ receptors to inhibit transmitter release (Dunwiddie, 1985; Lupica et al., 1992; Prince and Stevens, 1992), either by inhibiting voltage-dependent $\mathrm{Ca}^{2+}$ influx (Scholz and Miller, 1991; Yawo and Chuhma, 1993) or by another mechanism such as inhibition of adenylate cyclase (Dunwiddie and Fredholm, 1989; Scanziani et al., 1992; ChavezNoriega and Stevens, 1994). GABA, acting on $\mathrm{GABA}_{\mathrm{B}}$ receptors, inhibits glutamate release in a similar manner (Scanziani et al., 1992; Isaacson et al., 1993; Pfrieger et al., 1994). The role of adenosine and $\mathrm{GABA}_{\mathrm{B}}$ receptors in the cerebellum is poorly understood. The cerebellum contains a high level of adenosine, as well as $A_{1}$ receptors (but not $A_{2}$ receptors: Jarvis and Williams, 1989) on parallel fiber terminals, and a high level of 5' nucleotidase which converts AMP into adenosine (reviewed by Do et al., 1991). Adenosine is released by climbing fibers (Cuenod et al., 1989), and by granule cells (Schousboe et al., 1989) which provide the parallel fiber input to Purkinje cells, while GABA is released by basket, Golgi and stellate cells. Adenosine and GABA reduce parallel fiber to Purkinje cell transmission (Hackett, 1974; Kocsis et al., 1984; Batchelor and Garthwaite, 1992).

The results below show that the determinants of EPSC waveform at the parallel and climbing fiber to Purkinje cell synapses are different to those at the mossy fiber to granule cell synapse, and that adenosine and GABA affect differently the strengths of the parallel and climbing fiber synapses. 


\section{Materials and Methods}

All experiments were done at room temperature, $25^{\circ} \mathrm{C}$.

Cerebellar slices. Parasagittal slices (for EPSC experiments) or coronal slices (for recording the parallel fiber presynaptic vollcy) $200 \mu \mathrm{m}$ thick were cut from the cerebellum of rats (killed by cervical dislocation) on a vibrating slicer and submerged in flowing solution $(2 \mathrm{ml} /$ min). For EPSC experiments 10-15 (usually 12) d old rats were used, while for parallel fiber presynaptic volley experiments $18 \mathrm{~d}$ old rats were used because the increased number of parallel fibers in the slightly older animals facilitates recording of the presynaptic volley. Purkinje cell somata, identified by their position and size in the slice, were whole-cell clamped (with a Biologic (France) RK300 patch-clamp) using pipettes with series resistance (in whole-cell mode) around 5-20 $\mathrm{M} \Omega$ Pipette series resistance $\left(R_{1}\right.$ in the model of Llano et al., 1991) was obtained from fitting the capacity transient produced by a small voltage step to the prediction of a two compartment model, as in Llano et al. (1991) but without making assumptions about the relative sizes of the model parameters. Compensation (typically by $50 \%$ ) to reduce the effective series resistance was sometimes carried out (Llano et al., 1991)

Stimulation. The climbing or parallel fiber input to Purkinje cells was stimulated at $0.05-0.1 \mathrm{~Hz}$ with a bipolar theta glass electrode filled with $1 \mathrm{M} \mathrm{NaCl}$, as described previously (Konnerth et al., 1990; Perkel et al., 1990). The input was identified from stimulus-response curves (which checked that climbing fiber responses were less than $5 \%$ contaminated by parallel fiber responses), and by applying two stimuli at a short interval to see whether the second response was larger (parallel fiber input) or smaller (climbing fiber). For the parallel fiber compound action potential, which was recorded extracellularly with the patch-clamp (in voltage-clamp mode) using electrodes containing extracellular solution, stimuli producing a half-maximal response were used to enhance the chance of detecting any effect of adcnosine or baclofen on the number of fibers stimulated.

Solutions. Pipette solution contained (mM) $\mathrm{CsF} 110, \mathrm{CsCl} 30, \mathrm{NaCl}$ $4, \mathrm{CaCl}_{2} 0.5, \mathrm{Cs}_{2} \mathrm{EGTA} 5$, HEPES $10, \mathrm{pH}$ adjusted to 7.3 with $\mathrm{CsOH}$. External solution contained (mM) $\mathrm{NaCl} 124, \mathrm{KCl} 2.5, \mathrm{MgCl}_{2} 2, \mathrm{CaCl}_{2}$ $2.5, \mathrm{NaH}_{2} \mathrm{PO}_{4} 1, \mathrm{NaHCO}_{3} 26$, glucose 10 , picrotoxin 0.1 (to block GA$\mathrm{BA}_{\mathrm{A}}$ receptors, superimposing $0.02 \mathrm{~mm}$ bicuculline on picrotoxin produced no change of waveform); bubbled with $95 \% \mathrm{O}_{2}, 5 \% \mathrm{CO}_{2} ; \mathrm{pH}$ 7.4. For experiments on the presynaptic volley in the parallel fibers, 20 $\mu \mathrm{M} C N Q X$ was added to the external solution to block AMPA receptors. CNQX was made up as a stock solution in DMSO, and DMSO was also added to the control solution used in experiments employing this agent. Other drugs were added to the external solution from aqueous stock solutions or as solids (checking that they did not alter the $\mathrm{pH}$ ). Warming the solution and sonication facilitated the dissolving of diazoxide.

Iontophoresis. Electrodes filled with $100 \mathrm{~mm}$ sodium glutamate (resistance $100 \mathrm{M} \Omega$ ) were placed near Purkinje cell bodies and glutamate was ejected by switching from a holding current of $+20 \mathrm{nA}$ to an ejection current of $-40 \mathrm{nA}$. Experiments were done in calcium-free external solution ( $2.5 \mathrm{mM} \mathrm{CaCl}$ replaced by $2.5 \mathrm{mM} \mathrm{Na} 2 \mathrm{EGTA}$ ) to eliminate effects of glutamate on cells other than the Purkinje cell being transmitted synaptically to the Purkinje cell.

Predicted effect of series resistance on EPSC decay. To improve voltage control, cell somata were often clamped to around $-40 \mathrm{mV}$ to inactivate the cells' sodium currents, and a pipette solution containing cesium instead of potassium was employed. Earlier work suggests that in these conditions the climbing and parallel fiber EPSCs are reasonably well voltage clamped and their decay time constants are reasonably accurately measured (Llano et al., 1991; see also Häusser, 1994). We found no correlation of EPSC decay time constant with series resistance value when the series resistance was less than $15 \mathrm{M} \Omega$ Nevertheless, control experiments (described in the Results section) and theoretical calculations (described below) were performed to check that changes of EPSC waveform produced experimentally were not due to defective voltage control produced by series resistance errors.

The voltage drop generated by the synaptic current flowing across the series resistance, $R_{s}$, of the whole cell pipette leads to a distortion of the decay time course of EPSC. In the following analysis the cell capacitance and conductance are ignored: numerical simulations showed that including them reduced the speeding of the EPSC decay produced by the series resistance when the synaptic current is reduced with adenosine or baclofen, so the following is a worst case analysis. In addition the cell is treated as isopotential. A more accurate two compartment model of the cell is given by Llano et al. (1991). Series resistance alteration of the EPSC time course is most likely to occur for the climbing fiber synapses (because of their large current) most of which, in 12 $\mathrm{d}$ old rats, are likely to be located in the proximal compartment (soma and proximal dendrites) of the model of Llano et al. (1991) (see Altman, 1972; Llano et al., 1991, pp 203-204). In this situation $R_{s}$ in the following equations can be replaced by $R_{1}$ (or the uncompensated part of $R_{1}$ ) in the nomenclature of Llano et al. (1991).

The inward synaptic current, $I$, can be expressed as

$$
I=g_{\text {mах }} \exp (-t / \tau)\left(V_{\text {rev }}-V_{\text {cell }}\right),
$$

(where $V_{\text {rev }}$ is the reversal potential of the synaptic current and $V_{\text {cell }}$ is the voltage inside the cell), that is, as the product of an exponentially decaying conductance and the driving force on the current, and this current will generate a voltage drop across $R_{s}$ so that

$$
V_{\text {cell }}=V_{\text {pip }}+I R_{s}
$$

where $V_{\text {pip }}$ is the clamped pipette potential. Solving Equations 1 and 2 gives the observed (nonexponential) time course of the current as

$$
I=\frac{g_{\max }\left(V_{\mathrm{rev}}-V_{\mathrm{pip}}\right) \exp (-t / \tau)}{1+g_{\max } R_{S} \exp (-t / \tau)} .
$$

At the time when the underlying conductance has decreased to half its initial value, Equation 3 predicts the effective time decay constant of the observed current (given by $1 / \tau_{\mathrm{obs}}=-(1 / I) d I / d t$ ) as

$$
\begin{aligned}
\tau_{\mathrm{obs}} & =\tau\left(1+g_{\max } R_{S} / 2\right) \\
& =\tau\left(1+\left\{I_{\max } R_{S} / 2\right\} /\left\{V_{\text {rev }}-V_{\text {pip }}-I_{\max } R_{S}\right\}\right),
\end{aligned}
$$

where $I_{\text {max }}$ is the peak current at $t=0$. Thus, when adenosine or baclofen is used to decrease $g_{\max }$ (see Results), the observed decay time constant will decrease. If the resulting peak current is decreased by a fraction $f$, Equation 4 predicts a fractional change of observed time constant of

$$
\frac{\Delta \tau_{\text {obs }}}{\tau_{\text {obs }}}=\frac{f I_{\text {max }} R_{S}\left(V_{\text {rev }} V_{\text {pip }}\right)}{\left\{2\left(V_{\text {rev }}-V_{\text {pip }}\right)-I_{\text {max }} R_{S}\right\}\left\{V_{\text {rev }}-V_{\text {pip }}-(1-f) I_{\text {max }} R_{S}\right\}},
$$

where $I_{\max }$ is the peak current flowing in the absence of adenosine or baclofen. For each cell studied, Equation 5 was used to calculate the change of EPSC decay time constant expected from series resistance errors. Figure $4 C$ shows that for cells with low (uncompensated) series resistance, these errors generate only a small fraction (open squares) of the observed change of time constant (solid squares). For the data in Figure $4 C$ with $R_{s} I_{\max }<10 \mathrm{mV}$, the predicted fractional change of time constant due to series resistance errors is on average $24 \%$ of that actually observed.

The presence of series resistance error can also be shown to produce a small distortion of the dose-response curves describing the action of adenosine or baclofen on the peak synaptic current from that which would be observed for the underlying conductance. For typical values of series resistance (10 M $\Omega$ ) and synaptic current amplitude, mathematical analysis showed that this will lead to the adenosine dose needed to produce a half-maximal effect on the synaptic current being $12 \%$ higher for the climbing fiber, and $6 \%$ higher for the parallel fiber input, than that which has a half-maximal effect on the synaptic conductance.

Definition of second EPSC amplitude in paired pulse experiments. For paired pulse experiments in diazoxide (see Fig. 7) the current produced by the second stimulus starts from the decaying current tail produced by the first stimulus. Assuming that glutamate is released at the same sites by both stimuli (consistent with diazoxide increasing the size of the second response more than the first; see Results), we defined the amplitude of the second EPSC as the peak current measured relative to the baseline before the first stimulus (i.e., without subtracting the first EPSC tail), a definition different to that of Trussell et al (1993). This is because we are interested in the current produced by the amount of glutamate present in the synaptic cleft at the peak of the second EPSC: we assume this glutamate concentration is the same with or without diazoxide present, so the long current tail of the first EPSC in diazoxide reflects a prolonged presence of glutamate in the synaptic cleft which occurs even when diazoxide is absent (without diazoxide the glutamate generates no current because desensitization occurs and the receptor affinity may be lower). The long current tail in diazoxide $(\tau=48 \mathrm{msec})$ is unlikely to reffect slowed receptor deactivation because drugs blocking desensitization have only been shown to increase the deactivation 

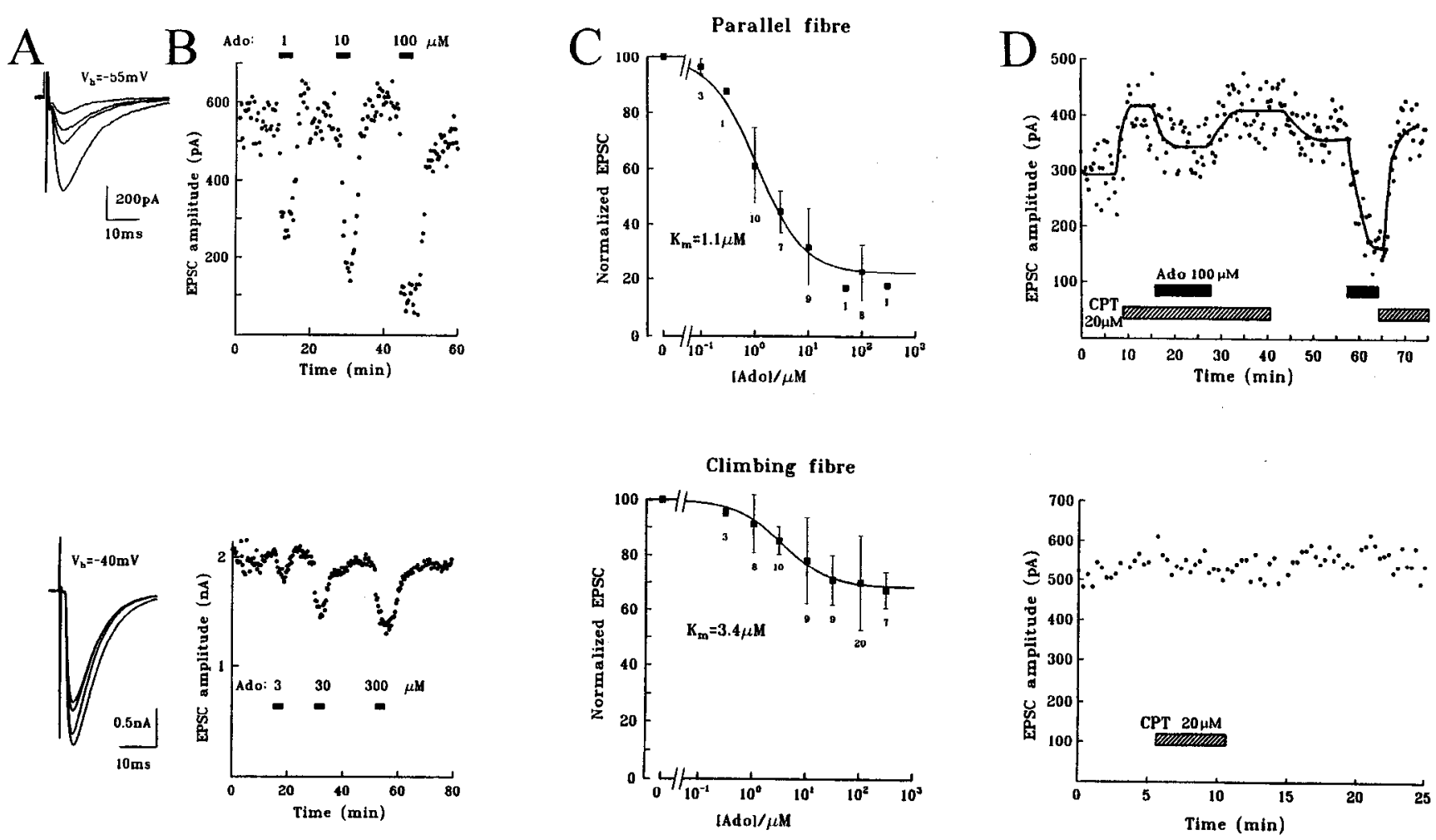

Figure 1. Suppressive effect of adenosine (Ado) on the EPSC evoked in Purkinje cells by stimulation of the parallel fiber (top) or climbing fiber (bottom) input. A, Specimen EPSCs recorded in control solution (largest amplitude current) and with increasing doses of superfused adenosine (smaller currents), 1, 10, and $100 \mu \mathrm{M}$ for the parallel fiber (holding potential $-55 \mathrm{mV}$ ) and 3, 30, and $300 \mu \mathrm{M}$ for the climbing fiber (holding potential $-40 \mathrm{mV}$ ). $B$, EPSC amplitude for the cells shown in $A$ as a function of time during application of different adenosine doses. $C$, Mean dose-response data ( \pm SEM) obtained as in $B$ at potentials between -30 and $-65 \mathrm{mV}$. Number of cells shown by each point. Curves best-fit through the points have the form $1-\left\{F_{\max }[\right.$ Ado $] /\left([\right.$ Ado $\left.\left.]+K_{m}\right)\right\}$, where $F_{\max }$ is the maximum fractional suppression (0.78 top, 0.31 bottom). $D$, Peak EPSC amplitude as a function of time (holding potential $=-66 \mathrm{mV}$ for the parallel, and $-51 \mathrm{mV}$ for the climbing fiber cell), during application of the $\mathrm{A}_{1}$ receptor blocker 8-cyclopentyl-theophylline $(C P T)$. Line through the points was drawn by eye. For the parallel fiber input, adenosine is shown to suppress the EPSC less in the presence of CPT than in its absence.

half-time to a few milliseconds (Trussell et al., 1993; Yamada and Tang, 1993; Barbour et al., 1994).

\section{Results}

Differential effects of adenosine and GABA on climbing fiber and parallel fiber synapses

EPSCs evoked by stimulating the climbing fiber or parallel fiber inputs to Purkinje cells in cerebellar slices are sliown in Figure 1. These EPSCs are mediated by non-NMDA receptors (Konnerth et al., 1990; Perkel et al., 1990). Superfused adenosine reduced the EPSC amplitude at both synapses (Fig. 1A,B), but the fractional suppression produced by high doses of adenosine was much larger for the parallel fiber synapses (78\%) than for the climbing fiber synapses $(31 \%)$. This reduction of EPSC amplitude is presumably due to a reduction of presynaptic glutamate release, as in the hippocampus (Lupica et al., 1992; Prince and Stevens, 1992). Postsynaptic effects of adenosine on potassium currents should be minimized by our use of cesium instead of potassium in the whole-cell pipette solution, and indeed adenosine did not alter the baseline current of the postsynaptic cell. Furthermore $100 \mu \mathrm{M}$ adenosine had little effect on the current generated by AMPA receptors in Purkinje cells in response to iontophoresed glutamate (reduced by $<5 \%$ in four cells, studied in zcro-calcium solution to eliminate trans-synaptic effects of glutamate; data not shown). Dose-response curves for the suppressive effect of adenosine on the EPSCs (Fig. 1C) could he fit empirically by Michaelis-Menten functions, and showed that the larger effect of adenosine on the parallel fiber synapses was not due to a large difference in apparent affinity for adenosine at the two synapses. The duse producing a half-maximal suppression was $1.1 \mu \mathrm{M}$ at the parallel, and $3.4 \mu \mathrm{M}$ at the climbing fiber synapse.

Evidence confirming that adenosine was reducing the EPSCs by acting on $A_{1}$ receptors came from experiments showing that the $A_{1}$ agonist cyclopentyl-adenosine, $10-100 \mu \mathrm{M}$ ) also reduced the EPSCs (in eight climbing fiber responses, data not shown), and from the fact that the $A_{1}$ receptor antagonist CPT blocked the action of adenosine (Fig. $1 D$ ). Applying CPT on its own polentiated the parallel fiber response [by $24 \pm 5$ (sem) \% in six cells] but had little effect on the climbing fiber response (Fig. $1 D$, data typical of three cells). This suggests that there is some tonic adenosine release in cerebellar slices which tonically suppresses the parallel fiber EPSC (the lack of effect on the climbing fiber EPSC being consistent with the lower sensitivity of this EPSC to adenosine). However, the potentiation of the parallel fiber EPSC in Figure $1 D$ is much less than the $200 \%$ potentiation seen for the hippocampal Schaffer collateral EPSC (Garaschuk et al., 1992).

In the presence of picrotoxin (to block $\mathrm{GABA}_{\mathrm{A}}$ receptors) $\mathrm{G} \wedge \mathrm{B} \Lambda\left(100 \mu \mathrm{M}\right.$, data not shown), and the $\mathrm{GABA}_{\mathrm{B}}$ receptor agonist baclofen, also reduced the parallel and climbing fiber EPSCs (Fig. 2A). The parallel fiher response was suppressed more $(93 \%)$ than the climbing fiber response (44\%) at high ba- 

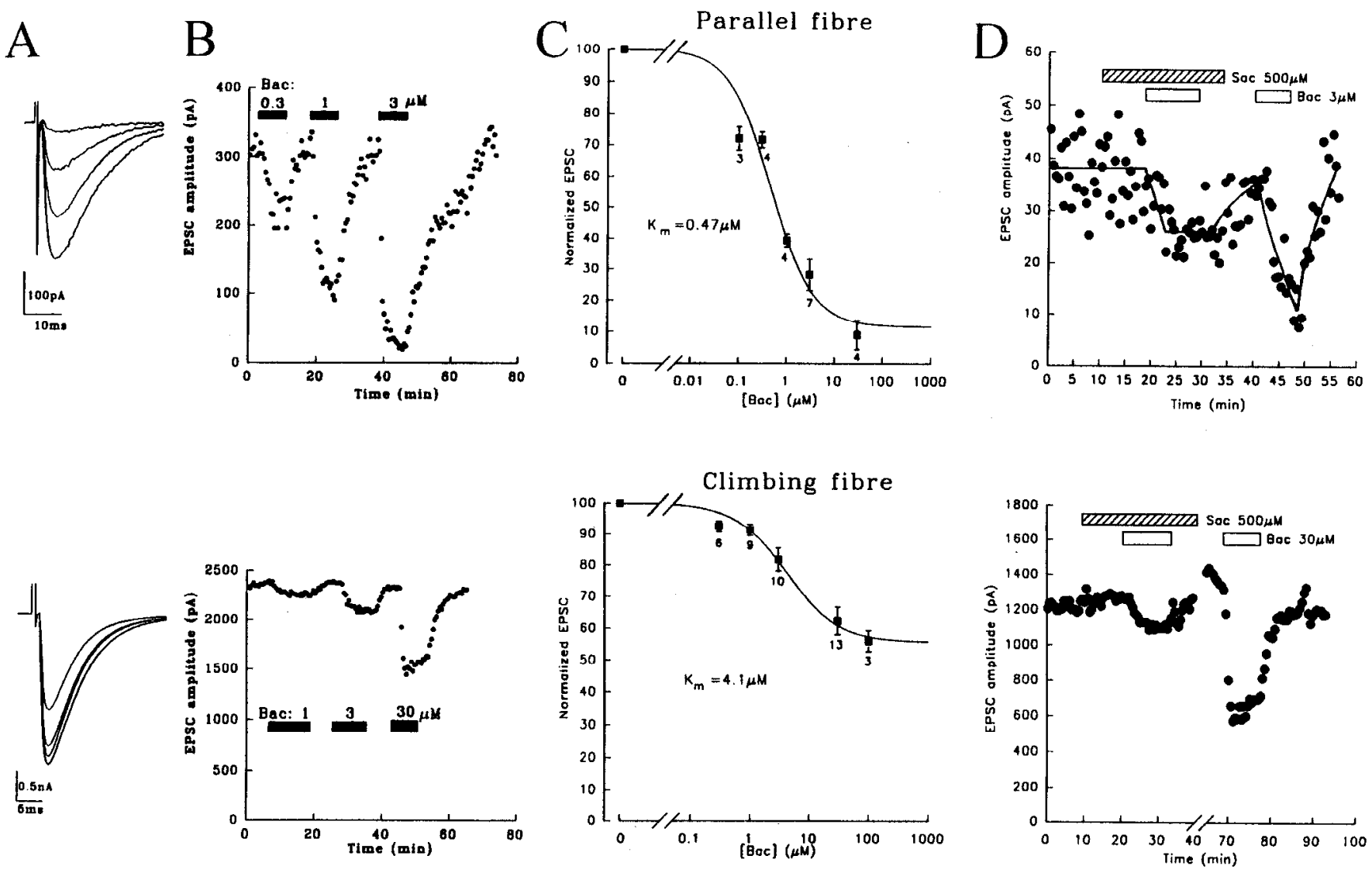

Figure 2. Suppressive effect of the GABA ${ }_{\mathrm{B}}$ agonist baclofen ( $\mathrm{Bac}$ ) on the EPSC evoked in Purkinje cells by stimulation of the parallel fiber (top) or climbing fiber (bottom) input. A, Specimen EPSCs recorded in control solution (largest amplitude current) and with increasing doses of superfused baclofen (smaller currents), $0.3,1$, and $3 \mu \mathrm{M}$ for the parallel fiber (holding potential $-32 \mathrm{mV}$ ) and 1, 3, and $30 \mu \mathrm{M}$ for the climbing fiber (holding potential $-36 \mathrm{mV}$ ). $B$, EPSC amplitude for the cells shown in $A$ as a function of time during application of different baclofen doses. $C$, Mean dose-response data ( \pm SEM) obtained as in $B$ at potentials between -25 and $-45 \mathrm{mV}$. Number of celis shown by each point. Curves best-fit through the points have the form $1-\left\{F_{\max }[\mathrm{Bac}] /\left([\mathrm{Bac}]+K_{m}\right)\right\}$, where $F_{\max }$ is the maximum fractional suppression $(0.93$ top, 0.44 bottom). $D$, Peak EPSC amplitude as a function of time (holding potential $=-36 \mathrm{mV}$ for the parallel and for the climbing fiber cells), during application of the $\mathrm{GABA}_{\mathrm{B}}$ receptor blocker 2-hydroxy-saclofen $(S a c)$. Line through the points was drawn by eye.

clofen doses, and there was some difference in the apparent affinity of the receptors at the two synapses (Fig. $2 B, C$ ). The reduction of the EPSC is presumably, as at other synapses (Scanziani et al., 1992; Isaacson et al., 1993; Pfrieger et al., 1994), due to a reduction of glutamate release from the presynaptic terminal. Effects due to gating of postsynaptic potassium channels by $\mathrm{GABA}_{\mathrm{B}}$ receptors should be minimized in our experiments by the use of cesium in the whole-cell pipette solution and baclofen did not affect the baseline current of the postsynaptic cell. Furthermore, $100 \mu \mathrm{M}$ baclofen had little effect on the current generated by AMPA receptors in Purkinje cells in response to iontophoresed glutamate (reduced by $<5 \%$ in five cells, data not shown). The $\mathrm{GABA}_{\mathrm{B}}$ antagonist 2-hydroxy-saclofen blocked the action of baclofen (Fig. $2 D$ ), but did not produce a tonic potentiation of the EPSC at the four parallel fiber and eight climbing fiber synapses tested, indicating little tonic release of GABA into the cerebellar slice.

These effects of adenosine and baclofen do not result from changes in the number of presynaptic afferents stimulated. In the case of the climbing fiber synapses, stimulus-response curves showed that there was only one climbing fiber sending input to each cell recorded from (or sometimes two climbing fibers, as found previously in young rats: Konnerth et al., 1990; Llano et al., 1991), and a failure of excitation would have been immediately apparent. For the parallel fibers, extracellular recording of the presynaptic compound action potential in $12 \mathrm{co}-$ ronal cerebellar slices showed that $100 \mu \mathrm{M}$ adenosine and 100 $\mu \mathrm{M}$ baclofen reduced the presynaptic volley by only $6 \%$ and $9 \%$, respectively, much less than the $80-90 \%$ reduction they produced in the EPSC amplitude.

\section{Reduction of transmitter release speeds the decay of the EPSCS}

As well as reducing the EPSC amplitude, at both the climbing and the parallel fiber synapses adenosine and baclofen speeded the decay of the EPSC (Fig. 3). For cells where the voltage error at the peak of the synaptic current due to the pipette series resistance was less than $10 \mathrm{mV}$ (see below), fitting the EPSC at the climbing fiber synapse by a single exponential showed that the normal decay time constant (mean \pm SEM 7.0 $\pm 0.4 \mathrm{msec}$ in 29 cells) was reduced by $17 \pm 2 \%$ ( 15 cells) by $10-300 \mu \mathrm{M}$ adenosine and by $18 \pm 4 \%$ ( 4 cells) by $3-30 \mu \mathrm{m}$ baclofen. At the parallel fiber synapse the normal decay time constant (mean value $10.7 \pm 0.8 \mathrm{msec}$ in 27 cells) was reduced by $14 \pm 2 \%$ (13 cells) by $10-100 \mu \mathrm{M}$ adenosine and by $14 \pm 2 \%$ ( 6 cells $)$ by $0.3-3 \mu \mathrm{M}$ baclofen.

A change of EPSC kinetics on reducing the amount of glutamate released could result from two kinds of artefact. First, if 
A

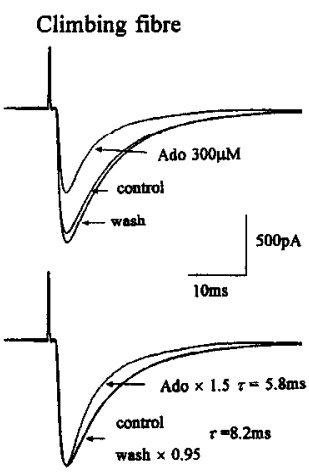

$\mathrm{C}$
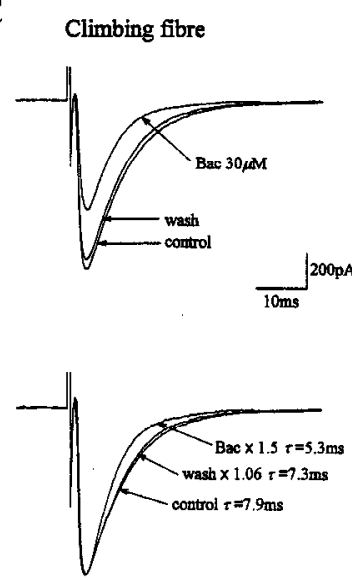

B
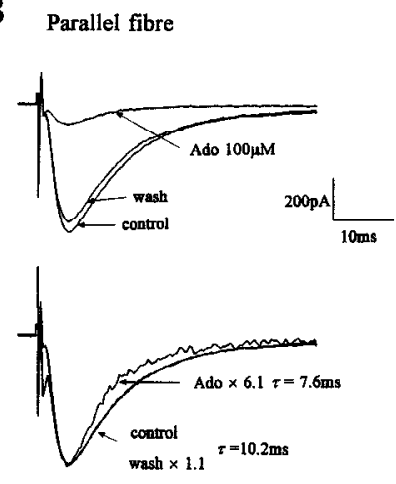

D
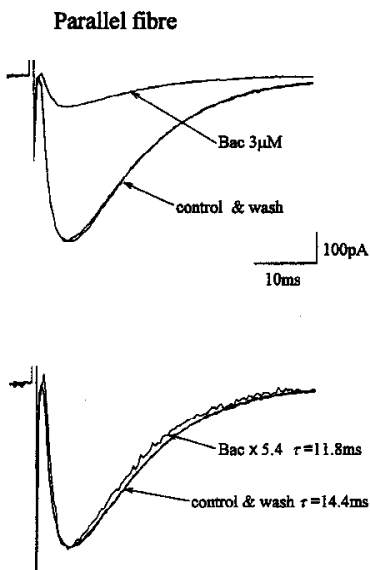

Figure 3. Effect of adenosine $(A, B)$ and baclofen $(C, D)$ on the decay of climbing fiber (left) and parallel fiber (right) EPSCs. Each pair of panels shows (top) the EPSCs recorded in control solution, in adenosine or baclofen, and then again in control solution (wash), and (bottom) the same EPSCs normalized to the same peak current. In the normalized plots the decay time constant, obtained from fitting a single exponential to the decay, is given. Holding potential was $-46 \mathrm{mV}$ and $-61 \mathrm{mV}$ for the climbing and parallel fiber cells to which adenosine was applied, and $-27 \mathrm{mV}$ and $-36 \mathrm{mV}$ for the climbing and parallel fiber cells to which baclofen was applied.

the EPSC significantly depolarized a poorly voltage-clamped cell (more of a problem for the larger climbing fibcr EPSCs), then voltage-gated currents might be activated and contribute to the FPSC waveform, and their contribution might be smaller when the EPSC amplitude was reduced, leading to an apparent change of EPSC waveform. Secondly, mathematical analysis (see Materials and Methods, and also Llano et al., 1991) indicates that the voltage drop across the series resistance of the whole-cell pipette is expected to result in a speeding of the EPSC decay kinetics when the EPSC is reduced in amplitude. To rule out these possibilities we carried out the experiments shown in Figure 4. First, the speeding of the EPSC decay was seen both at negative potentials, and at positive potentials where activation of voltage-gated currents would be different to that occurring at negative potentials (Fig. $4 A$, data typical of three cells: these experiments were done on the climbing fiber EPSC because it is larger and therefore more likely to be affected by this kind of artefact). Second, reducing the climbing fiber re sponse by around $70 \%$ postsynaptically (instead of by reducing glutamate release), by blocking AMPA receptors with $1 \mu \mathrm{M}$ CNQX (Fig. 4B), did not affect the decay of the EPSC at the

$\mathbf{A}$

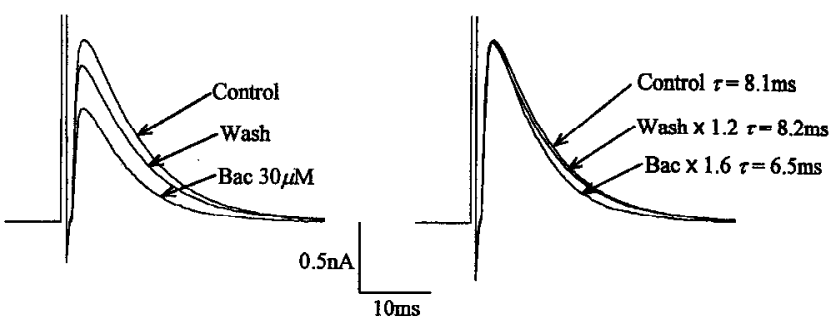

B

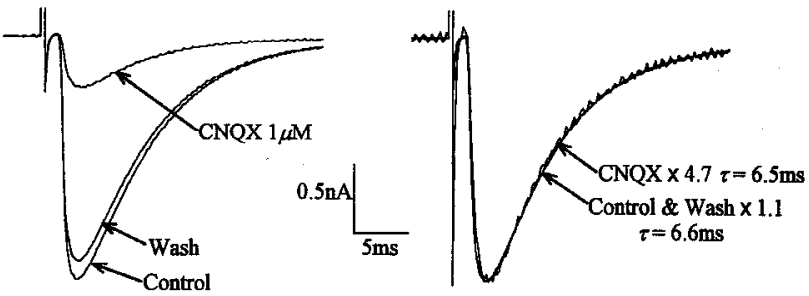

C

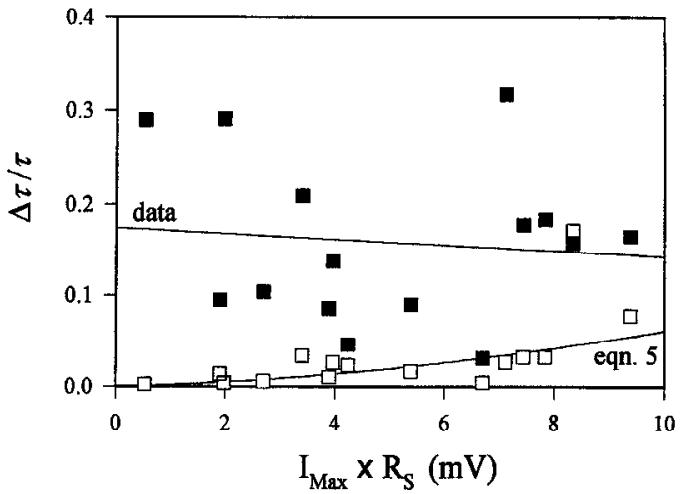

Figure 4. Speeding of the EPSC decay when glutamate release is reduced is not a result of series resistance-induced voltage errors. A, Baclofen speeded the climbing fiber EPSC decay at positive voltages (holding potential $+24 \mathrm{mV}$ ), as well as at negative voltages as in Figure 3. Left panel shows EPSCs in control solution, in baclofen, and again in control solution (Wash). Right panel shows the same data normalized to the same peak current. $B$, Postsynaptic reduction of the EPSC does not speed the EPSC decay. Left panel shows climbing fiber EPSCs (at $-37 \mathrm{mV}$ ) in control solution and in a dose of CNQX (1 $\mu \mathrm{M})$ chosen to produce a reduction of EPSC amplitude similar to that produced by baclofen or adenosine. Right panel shows the EPSC in CNQX scaled up to the amplitude of the control EPSC, to show the lack of any change of decay time constant. $C$, Fractional change of climbing fiber EPSC decay time constant, $\Delta \tau / \tau$, produced experimentally by $10-300 \mu \mathrm{M}$ adenosine (solid squares), and predicted theoretically from Equation 5 for the same cells to occur as a result of pipette series resistance (open squares), as a function of the peak voltage error produced by the pipette series resistance $R_{s}$ (the product of $R_{s}$ and the peak synaptic current, $I_{\max }$, in control solution, abscissa). Straight line is a best fit to the solid squares. Curve through open squares is a second order spline curve showing the trend of Equation 5.

climbing fiber synapse: the mean time constant in six cells was reduced by $0.5 \pm 5.2$ (SEM) \%, and the series resistance remaining uncompensated in these cells $(10.3 \pm 2.5 \mathrm{M} \Omega)$ was slightly larger than that for the cells to which adenosine and baclofen were applied ( $5.9 \pm 1.2$ and $9.2 \pm 8 \mathrm{M} \Omega$, respectively). A similar experiment showing CNQX having no effect on the kinetics of the EPSC at the parallel fiber synapse has been carried out by Barbour et al. (1994). Finally, for cells in which the series resistance voltage error was not excessive (peak EPSC $\times$ uncompensated series resistance $<10 \mathrm{mV}$ ), the speeding of the 


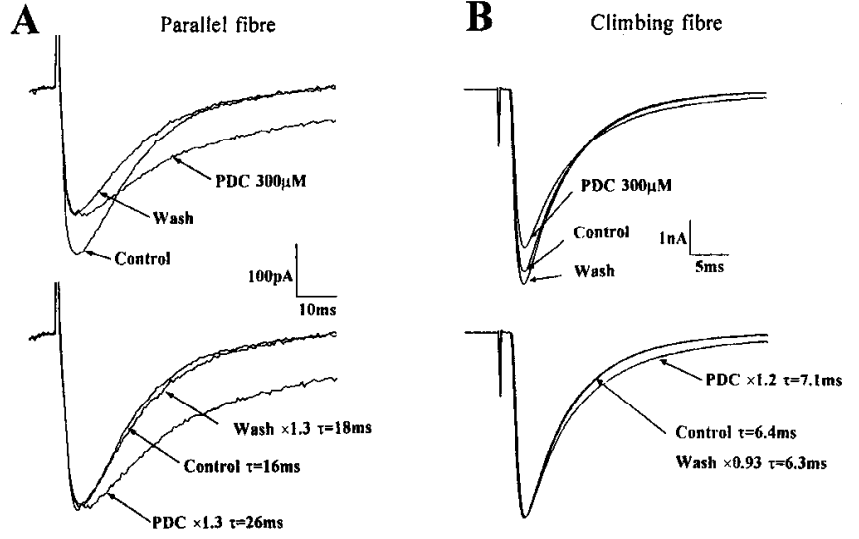

Figure 5. Inhibition of glutamate uptake prolongs the EPSC decay at the parallel fiber $(A)$ and climbing fiber $(B)$ synapses (holding potential $-36 \mathrm{mV}$ for both cells). Top panel for each synapse shows EPSCs in control solution, in the presence of the glutamate uptake blocker PDC and again in control solution (Wash). Bottom panel shows the same EPSCs normalized to the same peak current. Decay time constants were obtained by best fitting a single cxponcntial to the EPSC decay. In PDC the decays were better fit by the sum of two exponentials.

EPSC decay produced by $10-300 \mu \mathrm{M}$ adenosine at the climbing fiber synapse was found to be uncorrelated with the series resistance voltage error (Fig. $4 C$ ), and to be on average fourfold greater than the speeding predicted to occur as a result of the series resistance (from Equation 5 of Materials and Methods). A similar result was found for the effects of baclofen on the climbing fiber EPSC (and for the effects of adenosine and baclofen on the parallel fiber EPSCs, although for these the more distant synaptic location makes the applicability of Equation 5 uncertain since much of the series resistance may be along the dendrites rather than at the electrode tip).

We conclude that the speeding of the EPSC decay when transmitter release is reduced with adenosine or baclofen is not an artefact. One possible explanation of this speeding is that, when more glutamate is released from the presynaptic cell, it is cleared from the synaptic cleft more slowly. Slower glutamate removal might result from a reduced diffusion gradient for glutamate out of the synapse when more glutamate is released, as suggested by Trussell et al. (1993, their Fig. 7), or from saturation of glutamate uptake at high glutamate doses. To test the latter possibility, the experiments in the next section were carried out.

\section{Blocking glutamate uptake slows the decay of the EPSCS}

To test for a rate limiting role of glutamate removal in setting the EPSC decay rate, we used the glutamate uptake blocker L-trans-pyrrolidine-2,4-dicarboxylate (PDC, $300 \mu \mathrm{M}$ ). This should roughly halve the rate of uptake of $1 \mathrm{~mm}$ glutamate (Sarantis et al., 1993), which may be the peak concentration of glutamate in the synaptic cleft during the EPSC (Clements et al., 1992). PDC does not affect AMPA receptor currents (Sarantis et al., 1993).

Consistent with the results of Barbour et al. (1994), PDC prolonged the EPSC at the parallel fiber synapse (decay time constant increased by $101 \pm 27$ (SEM) \% in 12 cells) and, less dramatically, at the climbing fiber synapse (decay time constant increased by $10 \pm 2 \%$ in 6 cells), as shown in Figure 5. (In PDC the parallel fiber EPSC was better fit by the sum of two exponentials, rather than just one exponential: for simplicity here we characterize the slowing of the EPSC decay by using the time constant of a single exponential fitted to the part of the decay between approximately 80 and $10 \%$ of the peak current amplitude). In addition to slowing the EPSC decay, PDC reduced its amplitude at both synapses by $30-40 \%$, presumably because blocking uptake raises the extracellular glutamate level, [glu], in the slice and desensitizes the postsynaptic glutamate receptors. Consistent with a rise of [glu], PDC evoked a tonic inward current, as reported by Sarantis et al. (1993) and Barbour et al. (1994). The slowing of the EPSC decay time constant cannot reflect an effect of desensitization on the deactivation rate, because predesensitization apparently speeds deactivation (Colquhoun et al., 1992, their Fig. 14). These data suggest that there may be a prolonged glutamate transient in the synaptic cleft at these two synapses, and that the rate of glutamate removal affects the EPSC decay rate.

\section{Interaction of receptor desensitization and glutamate release in setting the EPSC decay rate}

If there is a prolonged glutamate transient in the synaptic cleft, then one might expect AMPA receptor desensitization to contribute to setting the decay time of the EPSC: desensitization typically occurs on a time scale of $1-15 \mathrm{msec}$ (Colquhoun et al., 1992; Raman and Trussell, 1992; Barbour et al., 1994) similar to the EPSC decay time constant at the parallel and climbing fiber synapses. Such desensitization could explain the fact that, as in calyceal synapses (Trussell et al., 1993), the EPSC evoked by the second of two closely spaced climbing fiber stimuli is smaller than the EPSC evoked by the first stimulus (Konnerth et al., 1990; Perkel et al., 1990). (This is not seen for the parallel fiber synapse because a second stimulus to the parallel fibers excites more fibers (Merrill et al., 1978) and thus produces a larger EPSC (Konnerth et al., 1990; Perkel et al., 1990) despite any desensitization occurring). Unlike at some synapses (Davies et al., 1990), paired pulse depression at the climbing fiber synapse is not due to GABA release from interneurons after the first stimulus suppressing glutamate release to the second stimulus: in nine cells 2-hydroxysaclofen $(500 \mu \mathrm{M})$ had no effect on the ratio of the second EPSC amplitude to that of the first EPSC (increased by only $0.9 \pm 1.5 \%$ ).

We investigated how reducing glutamate release with adenosine or baclofen affected the EPSCs evoked by twin stimuli to the climbing fibers. The rationale behind the experiment was that reducing glutamate relcase should result in lcss desensitization at the time of the second EPSC (cf. Trussell et al., 1993). As a result adenosine or baclofen is expected to produce less reduction of the second EPSC than of the first. This prediction was found to be correct, indeed adenosine often increased the amplitude of the second EPSC while decreasing the amplitude of the first (Fig. 6), presumably because the increase in amplitude of the second EPSC resulting from less desensitization outweighed the reduction in amplitude produced by less glutamate release. For stimuli separated by $30-55 \mathrm{msec}$, in 22 cells 100 $\mu \mathrm{M}$ adenosine decreased the first EPSC by $32 \pm 3 \%$ but did not significantly affect the second EPSC (decreased by $2 \pm 5 \%$ ). Corresponding figures for $100 \mu \mathrm{M}$ baclofen ( 3 cells) were $43 \pm$ $4 \%$ and $20 \pm 6 \%$.

A decreased sensitivity of the second response to a blockade of presynaptic calcium entry, as described above, might be attributed to a presynaptic effect, for example decreasing the number of vesicles released on the first pulse might leave more to be released by the second pulse. The interpretation given above in terms of desensitization could be tested by blocking desen- 

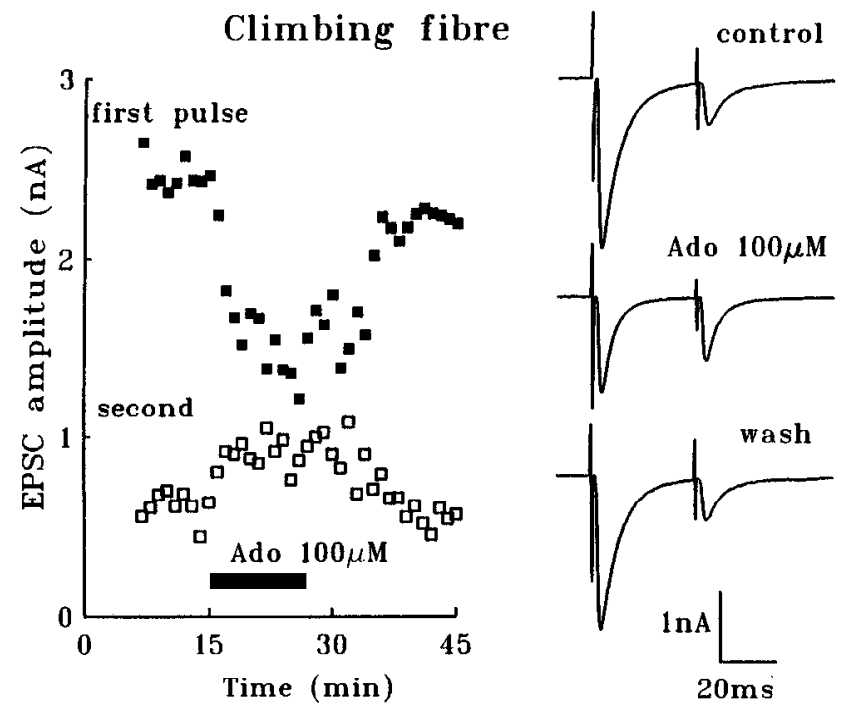

Figure 6. Differential effect of adenosine (Ado) on the first and second of two EPSCs evoked by twin pulse stimulation of the climbing fiber input to a Purkinje cell. Right, Specimen EPSCs in control solution, adenosine, and after washing adenosine out (stimulus timing shown by sharp stimulus artifacts on current traces). Left, Amplitude of the first (solid square) and second (open square) EPSCs as a function of time during the experiment. Holding potential, $-51 \mathrm{mV}$.

sitization: in this situation adenosine (or baclofen) should reduce both EPSCs equally. To test this, we applied diazoxide $(500 \mu \mathrm{M})$ which, among other effects, reduces desensitization of AMPA receptors (Yamada and Rothman, 1992). At both the parallel fiber synapse (not shown) and at the climbing fiber synapse (Fig. $7 B$ ) diazoxide greatly prolonged the EPSC decay (in nine cells the climbing fiber time constant increased from $7.5 \pm 0.7 \mathrm{msec}$ in control solution to $48 \pm 6 \mathrm{msec}$ in diazoxide; in two cells the parallel fiber time constant increased from $11.2 \pm 2.1$ to $27.6 \pm 4.2 \mathrm{msec}$ ). This result was also found by Barbour et al. (1994) who blocked desensitization with aniracetam (and also showed that this only increased the deactivation time constant from about $1 \mathrm{msec}$ to about $2 \mathrm{msec}$ ). The slowing of the EPSC decay is unlikely to be due to diazoxide inhibiting glutamate uptake: control experiments on salamander glial cells (as in Sarantis et al., 1993) showed that $500 \mu \mathrm{M}$ diazoxide slightly speeded uptake (the uptake current produced by $200 \mu \mathrm{M}$ glutamatc was increased by $17 \pm 8 \%$ in three cells). In addition diazoxide potentiated the second of two climbing fiber EPSCs more than it potentiated the first EPSC as shown in Figure $7 B$ (see also Trussell et al., 1993; Barbour et al., 1994): in nine cells the ratio of the second EPSC amplitude (defined as described in Materials and Methods) to the first EPSC amplitude was $0.60 \pm 0.02$ (SEM) in control solution and $0.84 \pm 0.02$ in diazuxide. In fou of the nine cells studied $30 \mu \mathrm{M}$ glibenclamide was applied with the diazoxide, to prevent diazoxide activating ATP-gated potassium channels (Quast and Cook, 1989; Yamada and Rothman, 1992) and the results obtained were identical to those in the five cells studied without glibenclamide. Thus these effects of diazoxide do not reflect a change of glutamate release produced by activation of presynaptic ATP-gated potassium channels. Both the effects of diazoxide are consistent with desensitization contributing to the second EPSC being smaller, and to setting the EPSC decay time course, with the longer EPSC seen in diazoxide being a more faithful reflection of the underlying glutamate transient in the synaptic cleft (but see Discussion).

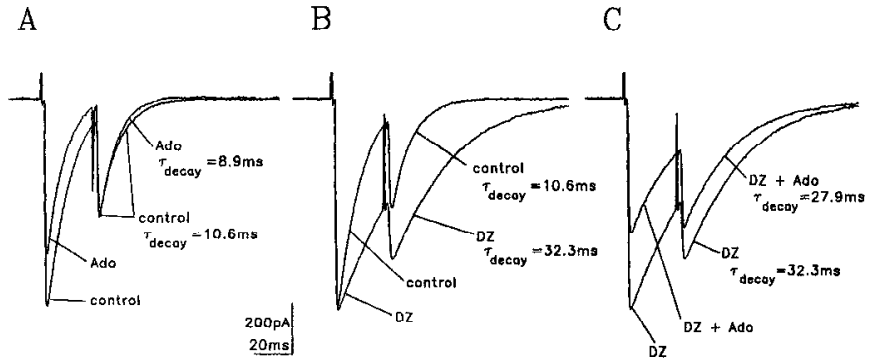

Figure 7. Effect of diazoxide (DZ), which removes AMPA receptor desensitization, on the EPSCs evoked in a Purkinje cell by twin pulse stimulation of its climbing fiber input (stimulus timing shown by sharp artifacts on the current traces). $A$, In control solution the second of two EPSCs is smaller than the first, and adenosine $($ Ado, $100 \mu \mathrm{M})$ reduces the first EPSC much more than the second. $B$, Diazoxide $(500 \mu \mathrm{M})$ prolongs both EPSCs, and increases the second EPSC more than the first. $C$ In diazoxide, adenosine has a more similar effect on the first and second EPSCs. Holding potential, $-25 \mathrm{mV}$.

Applying adenosine $(100 \mu \mathrm{M})$ in the presence of diazoxide (Fig. 7C) led to the second EPSC being suppressed (by $13 \pm$ $2 \%$ in nine cells) almost as much as the first EPSC was suppressed (by $18 \pm 3 \%$ ), as expected with desensitization greatly reduced (and in contrast to what is seen in the absence of diazoxide: Figs. 6, 7A). Thus, for brief intervals between presynaptic action potentials the climbing fiber EPSC size and kinetics will be set by an interaction between the amount of glutamate released presynaptically and the amount of desensitization occurring postsynaptically.

\section{Discussion}

These experiments give insight into four aspects of the operation of the excitatory synapses from parallel and climbing fibers to cerebellar Purkinje cells: the differential control of synaptic strength at different synapses by presynaptic receptors, the effect of the amount of glutamate released on the speed of the EPSC decay, the role of glutamate uptake in terminating the synaptic current, and the role of receptor desensitization.

\section{Differential control of synaptic strength by presynaptic receptors}

Both adenosine and GABA (baclofen) had a much stronger suppressive effect on the EPSC at the parallel fiber synapse than at the climbing fiber synapse (see also Hackett, 1974; Kocsis et al., 1984). Functionally, this may correlate with the notion (Marr, 1969) that the powerful climbing fiber input is an all-or-none signal triggering adjustment of the parallel fiber synaptic gains, so that subtle modulation of its strength by presynaptic receptors is not required. However, during ischemia, suppression of glutamate release by release of adenosine (Hagberg et al., 1987) is neuroprotective (Goldberg et al., 1988; Fowler, 1990; Gribkoff and Bauman, 1992; Rudolphi et al., 1992), and it is not obvious why such a protective mechanism is not employed at the climbing fiber synapse. Interestingly, of cerebellar neurons, Purkinje cells are particularly vulnerable to ischemic damage (Brierley and Graham, 1984), triggered by activation of non-NMDA receptors (Balchen and Diemer, 1992).

Dependence of the EPSC duration on the amount of glutamate released

Reducing the amount of glutamate released, using adenosine or a $\mathrm{GABA}_{\mathrm{B}}$ receptor agonist, speeded the decay of the EPSC at 
both the climbing fiber and the parallel fiber to Purkinje cell synapses. In principle this could be a purely presynaptic effect, if the duration of the EPSC partly reflects temporal dispersion in the rclcasc of different vesicles of transmitter, and if reducing transmitter release with adenosine and GABA increases synchrony in the release of different vesicles. However, the effects of blocking glutamate uptake and of removing AMPA receptor desensitization suggest a more parsimonious explanation in which some glutamate remains in the synaptic cleft for a significant fraction of the EPSC duration (at least $5-10 \mathrm{msec}$ ). In this case, the rate of removal of glutamate from the cleft is one factor determining the EPSC duration. Reducing the amount of glutamate released can then result in a faster EPSC decay for one of three reasons. First, there may be a larger extracellular concentration gradient for diffusion of glutamate out of the synaptic cleft, so the glutamate concentration falls with a faster time constant, as suggested by Trussell et al. (1993, their Fig. 7). Second, the glutamate concentration may fall with a faster time constant because glutamate uptake is less saturated. Finally, even if the glutamate concentration ([glu]) falls with the same time constant $\left(\tau_{\mathrm{glu}}\right)$, saturation of the dose-response curve for glutamate activating AMPA receptors can result in a faster EPSC decay when the peak glutamate concentration is lower, as described by Sarantis et al. (1993, Materials and Methods): the time constant of the EPSC decay (in a situation where deactivation is much quicker than the decay of [glu] and there is no desensitization) is given by $\tau_{I}=\tau_{\mathrm{glu}}\left\{1+([\mathrm{glu}] / K)^{n}\right\} / n$, where $K$ is the $\mathrm{EC}_{50}$ for glutamate activating AMPA receptors, and $\mathrm{n}$ is the Hill coefficient for that activation, so $\tau_{l}$ is smaller when [glu] is smaller.

These explanations for how reduced release could speed the EPSC decay assume that a reduction of release decreases the [glu] seen by all the postsynaptic receptors. This is appropriate if each release site normally releases several vesicles per action potential, and adenosine or baclofen decreases the number released. However, it is possible that each site normally releases only one vesicle, and that adenosine or baclofen stops release completely at some sites (where the release probability is then 0 ) while leaving the release and the [glu] transient unaltered at other, spatially separate, release sites. There is no information available on the number of vesicles released at single release sites at parallel and climbing fiber synapses. However, for the climbing fiber, the relatively open extracellular space between different release sites (onto different Purkinje cell dendritic "thorns": Palay and Chan-Palay, 1974) may well result in a reduced [glu] at all postsynaptic receptors even if only a fraction of release sites stop releasing in the presence of adenosine or baclofen (i.e., there may well be cross talk between different release sites).

\section{Role of glutamate uptake in terminating the EPSC}

Blocking glutamate uptake prolonged the EPSC at both the climbing and the parallel fiber to Purkinje cell synapses (see also Barbour et al., 1994), consistent with the rate of removal of glutamate from the synaptic cleft partly determining the EPSC duration. This is in contrast to the behavior of cerebellar mossy tiber to granule cell synapses and hippocampal Schaffer collateral to pyramidal cell synapses where blocking uptake has no cffect on the EPSC decay (Hcstrin et al., 1990; Isaacson and Nicoll, 1993; Sarantis et al., 1993). These differential effects of blocking uptake on the EPSCs at the three cerebellar synapses correlate with the fact that mossy fiber terminals do not express much glutamate uptake, unlike climbing fiber terminals and the granule cells which provide the parallel fiber terminals (Wilklund et al., 1982; Garthwaite and Garthwaite, 1988). The dramatic effect of uptake block on the parallel fiber EPSC in our experiments (Fig. 5A) may be due partly to a number of parallel fibers being stimulated (perhaps 20 for Fig. 5A: Barbour, 1993); removal of glutamate by diffusion out of the synaptic cleft may be more important if only one parallel fiber is active and the extracellular [glu] around the synapse is not raised by glutamate diffusing from release sites on nearby parallel fibers.

An effect of uptake rate on EPSC duration has also been found for synapses in cultured hippocampal neurons when desensitization is blocked (Mennerick and Zorumski, 1994a,b). By contrast Tong and Jahr (1994) found that blocking uptake did not affect the EPSC decay: this may be because the [glu] falls more rapidly at their cultured synapses than at the cerebellar synapses we have studied, due to the good diffusive contact with the bath solution, so the EPSC decay rate is dominated by the time course of receptor deactivation.

\section{Does receptor desensitization contribute to the EPSC decay?}

The changes of the EPSC decay produced by decreasing glutamate release or blocking glutamate uptake suggest that the glutamate transient in the synaptic cleft decays on a time scale comparable to that of the EPSC. A prolonged glutamate transient could result in some of the decay of the EPSC being due to AMPA receptor desensitization, which in other preparations proceeds with a time constant of $1-15 \mathrm{msec}$ (Colquhoun et al., 1992; Raman and Trussell, 1992). Consistent with this, diazoxide, which reduces desensitization (Yamada and Rothman, 1992), prolonged the EPSC at both the climbing fiber and parallel fiber synapses, and reduced the paired pulse depression seen when two climbing fiber stimuli are applied separated by a brief interval. Similar effects of agents which remove desensitization on the EPSC at cochlear nucleus and Purkinje cell synapses have been interpreted as proving that desensitization contributes to terminating the EPSC (Trussell et al., 1993; Barbour et al., 1994). However, agents like diazoxide have effects other than removal of desensitization. First, they prolong deactivation time, although apparently not enough to explain the lengthening of the EPSC produced (Trussell et al., 1993; Barbour et al., 1994). Second, they may increase the AMPA receptor affinity for glutamate (Patneau et al., 1993; Yamada and Tang, 1993) and could thus generate a large long lasting current decay from a small tail of elevated glutamate concentration in the synaptic cleft. This alternative explanation for the effect of diazoxide on the EPSC decay would require, though, that the glutamate transient in the synaptic cleft decays on a time scale longer than the EPSC seen in the absence of diazoxide, and so would in any case be likely to produce desensitization during the EPSC.

The effects of adenosine in the absence and presence of diazoxide also suggest a role for desensitization in setting the amplitude of the second of two closely spaced EPSCs (Figs. 6, 7). In the absence of diazoxide adenosine could increase the amplitude of the second EPSC while reducing the first EPSC, presumably because, by reducing glutamate release on the first stimulus, it reduced desensitization at the time of the second stimulus. By contrast, in the presence of diazoxide adenusine reduced both the first and second EPSCs, as expected with desensitization removed.

Thus, desensitization is one determinant of the climbing fiber 
EPSC amplitude and duration, and the glutamate transient in the synaptic cleft outlasts the EPSC seen in normal solution. It may be wondered how both desensitization and uptake can contribute to shaping the EPSC, when complete desensitization to a high maintained [glu] occurs with a time constant of around $4 \mathrm{msec}$ (Barbour et al., 1994). The answer may lie in the [glu]-dependence of desensitization: the fall of [glu] occurring after the EPSC peak may slow desensitization or make it less complete, so that the current seen late in the EPSC can be increased either by removing desensitization or by prolonging the [glu] transient (with an uptake blocker) and thus increasing the number of (nondesensitized) channels activated at late times. Alternatively, desensitization may set the EPSC duration at the (possibly saturated) receptors opposite a presynaptic release site, with uptake determining how far glutamate diffuses laterally in the synaptic cleft: inhibiting uptake could then allow more lateral diffusion and later activation of receptors at a distance from the release site (cf. Isaacson et al., 1993).

\section{Determinants of the EPSC duration at different cerebellar synapses}

From the experiments reported here it appears that a number of factors contribute to determining the EPSC duration at the parallel and climbing fiber synapses: the amount of glutamate released presynaptically, the rate of glutamate uptake, and the rate of AMPA receptor desensitization. By contrast the fast decay of the cerebellar mossy fiber to granule cell synapse is dominated by the speed of receptor deactivation following fast removal of glutamate from the synaptic cleft (Silver et al., 1992, 1994; Sarantis et al., 1993). It remains to be determined whether these differences are of functional importance for the operation of the cerebellum.

\section{References}

Altman II (1972) Postnatal development of the cerebellar cortex in the rat. II. Phases in the maturation of Purkinje cells and of the molecular layer. J Comp Neurol 145:399-464.

Balchen T, Diemer NH (1992) The AMPA antagonist, NBQX, protects against ischemia-induced loss of cerebellar Purkinje cells. Neuroreport 3:785-788.

Barbour B (1993) Synaptic currents evoked in Purkinje cells by stimulating individual granule cells. Neuron 11:759-769.

Barbour B, Keller BU, Llano I, Marty A (1994) Prolonged presence of glutamate during excitatory synaptic transmission to cerebellar Purkinje cells. Neuron 12:1331-1343.

Batchelor AM, Garthwaite J (1992) $\mathrm{GABA}_{\mathrm{B}}$ receptors in the parallel fiber pathway of rat cerebellum. Eur J Neurosci 4:1059-1064.

Brierley JB, Graham DI (1984) Hypoxia and vascular disorders of the central nervous system. In: Greenfields's neuropathology, 4th ed (Adams JH, Corsellis JAN, Duchen LW, eds), pp 127-207. London: Arnold.

Chavez-Noriega LE, Stevens CF (1994) Increased transmitter release at excitatory synapses produced by direct activation of adenylate cyclase in rat hippocampal slices. J Neurosci 14:310-317.

Clements JD, Lester RAJ, Tong G, Jahr CE, Westbrook GL (1992) The time course of glutamate in the synaptic cleft. Science 258:14981501.

Colquhoun D, Jonas P, Sakmann B (1992) Action of brief pulses of glutamate on AMPA/kainate receptors in patches from different neurones of rat hippocampal slices. J Physiol (Lond) 458:261-287.

Cuenod M, Do K-Q, Vollenweider F, Zollinger M, Klein A, Streit P (1989) The puzzle of the transmitters in the climbing fibers. Exp Brain Res 17:161-176.

Davies CH, Davies SN, Collingridge GL (1990) Paired-pulse depression of monosynaptic GABA-mediated inhibitory postsynaptic responses in rat hippocampus. J Physiol (Lond) 424:513-531.

Do KQ, Vollenweider FX, Zollinger M, Cuenod M (1991) Effect of climbing fibre deprivation on the $\mathrm{K}^{+}$-evoked release of endogenous adenosine from rat cercbellar slices. Eur $\mathbf{J}$ Ncurosci 3:201-208.

Dunwiddie TV (1985) The physiological role of adenosine in the central nervous system. Int Rev Neurobiol 27:63-139.

Dunwiddie TV, Fredholm BB (1989) Adenosine A, receptors inhibit adenylate cyclase activity and neurotransmitter release and hyperpolarize pyramidal neurons in rat hippocampus. $J$ Pharm Exp Ther 249:31-37.

Fowler JC (1990) Adenosine antagonists alter the synaptic response to in vitro ischemia in the rat hippocampus. Brain Res 509:331-334.

Garaschuk O, Kovalchuk Y, Krishtal O (1992) Adenosine-dependent enhancement by methylxanthines of excitatory synaptic transmission in hippocampus of rats. Ncurosci Lett 135:10-12.

Garthwaite G, Garthwaite J (1988) Electron microscopic autoradiography of $\mathrm{D}-\left[{ }^{3} \mathrm{H}\right]$ aspartate uptake sites in mouse cerebellar slices shows poor labelling of mossy fibre terminals. Brain Res 440:162-166.

Goldberg MP, Monyer H, Weiss JH, Choi DW (1988) Adenosine reduces cortical neuronal injury induced by oxygen or glucose deprivation in vitro. Neurosci Lett 89:323-327.

Gribkoff VK, Bauman LA (1992) Endogenous adenosine contributes to hypoxic synaptic depression in hippocampus from young and aged rats. J Neurophysiol 68:620-628.

Hackett JT (1974) GABA selectively blocks parallel fibre to Purkinje cell synaptic transmission in the frog cerebellum in vitro. Brain Res 80:527-531.

Hagberg H, Andersson P, Lacarewicz J, Jacobson I, Butcher S, Sandberg M (1987) Extracellular adenosine, inosine, hypoxanthine, and xanthine in relation to tissue nucleotides and purines in rat striatum during transient ischemia. $J$ Neurochem 49:227-231.

Häusser M (1994) Kinetics of excitatory postsynaptic current in Purkinje cells studied using dendritic patch-clamp recording. Soc Neurosci Abstr 20:891.

Hestrin S, Sah P, Nicoll RA (1990) Mechanisms generating the time course of dual component excitatory synaptic currents recorded in hippocampal slices. Neuron 5:247-253.

Isaacson JS, Nicoll RA (1993) The uptake inhibitor L-trans-PDC enhances responses to glutamate but fails to alter the kinetics of excitatory synaptic currents in the hippocampus. J Neurophysiol 70:21872191.

Isaacson JS, Solis JM, Nicoll RA (1993) Local and diffuse actions of GABA in the hippocampus. Neuron 10:165-175.

Jarvis MF, Williams M (1989) Direct autoradiographic localization of adenosine $A_{2}$ receptors in the rat brain using the $A_{2}$-selective agonist, $\left[{ }^{3} \mathrm{H}\right] \mathrm{CGS} 21680$. Eur J Pharmacol 168:243-246.

Kocsis JD, Eng DL, Bhisitkul RB (1984) Adenosine selectively blocks parallel-fiber-Inediated synaptic potentials in rat cerebellar cortex. Proc Natl Acad Sci USA 81:6531-6534.

Konnerth A, Llano I, Armstrong CM (1990) Synaptic currents in cerebellar Purkinje cells. Proc Natl Acad Sci USA 87:2662-2665.

Linden DJ, Connor JA (1993) Cellular mechanisms of long-term depression in the cerebellum. Curr Opin Neurobiol 3:401-406.

Llano I, Marty A, Armstrong CM, Konnerth A (1991) Synaptic- and agonist-induced excitatory currents of Purkinje cells in rat cerebellar slices. J Physiol (Lond) 434:183 213.

Lupica CR, Proctor WR, Dunwiddie TV (1992) Presynaptic inhibition of excitatory synaptic transmission by adenosine in rat hippocampus: analysis of unitary EPSP variance measured by whole-cell recording. J Neurosci 12:3753-3764.

Marr D (1969) A theory of cerebellar cortex. J Physiol (Lond) 202: $437-470$.

Mennerick S, Zorumski CF (1994a) Glial contributions to excitatory neurotransmission in cultured hippocampal cells. Nature 368:59-62.

Mennerick S, Zorumski CF (1994b) Presynaptic influences on the decay of excitatory synaptic currents. Soc Neurosci Abstr 20:1336.

Merrill EG, Wall PD, Yaksh TL (1978) Properties of two unmyelinated fibre tracts of the central nervous system: lateral lissauer tract and parallel fibres of the cerebellum. J Physiol (Lond) 284:127-145.

Palay SL, Chan-Palay V (1974) Cerebellar cortex. New York: Springer.

Patneau DK, Vyklicky L Jr, Mayer ML (1993) Hippocampal neurons exhibit cyclothiazide-sensitive rapidly desensitizing responses to kainate. J Neurosci 13:3496-3509.

Perkel DJ, Hestrin S, Sah P, Nicoll RA (1990) Excitatory synaptic currents in Purkinje cells. Proc Roy Soc Lond [Biol] 241:116-121.

Pfrieger FW, Gottmann K, Lux HD (1994) Kinetics of GABA ${ }_{B}$ recep- 
tor-mediated inhibition of calcium currents and excitatory synaptic transmission in hippocampal neurons in vitro. Neuron 12:97-107.

Prince DA, Stevens CF (1992) Adenosine decreases neurotransmitter release at central synapses. Proc Natl Acad Sci USA 89:8586-8590.

Quast U, Cook NS (1989) In vitro and in vivo comparison of two $\mathrm{K}^{+}$ channel openers, diazoxide and cromokalim, and their inhibition by glibenclamide. J Pharmacol Exp Ther 250:261-271.

Raman IM, Trussell LO (1992) 'The kinetics of the response to glutamate and kainate in neurons of the avian cochlear nucleus. Neuron 9:173-186.

Rudolphi KA, Schubert P, Parkinson FE, Fredholm BB (1992) Neuroprotective role of adenosine in cerebral ischaemia. Trends Pharmacol Sci 13:439-445.

Sarantis M, Ballerini L, Miller B, Silver RA, Edwards M, Attwell D (1993) Glutamate uptake from the synaptic cleft does not shape the decay of the non-NMDA component of the synaptic current. Neuron 11:541-549.

Scanziani M, Capogna M, Gähwiler BH, Thompson SM (1992) Presynaptic inhibition of miniature excitatory synaptic currents by baclofen and adenosine in the hippocampus. Neuron 9:919-927.

Scholz KP, Miller RJ (1991) Analysis of adenosine actions on $\mathrm{Ca}^{2+}$ currents and synaptic transmission in cultured rat hippocampal pyramidal neurones. J Physiol (Lond) 435:373-393.

Schousboe A, Fransden A, Drejer J (1989) Evidence for evoked release of adenosine and glutamate from cultured cerebellar granule cells. Neurochem Res 11:871-875.

Silver RA, Traynelis SF, Cull-Candy SG (1992) Rapid-time-course miniature and evoked excitatory currents at cerebellar synapses in situ. Nature 355:163-166.

Silver RA, Colquhoun D, Cull-Candy SG, Edmonds B (1994) Mechanisms underlying decay of the fast component of EPSCs in cerebellar granule cells. J Physiol (Lond) 476:67P-68P.

Tong G, Jahr CE (1994) Block of glutamate transporters potentiates postsynaptic excitation. Neuron 13:1195-1203.

Trussell LO, Zhang S, Raman IM (1993) Desensitization of AMPA receptors upon multiquantal neurotransmitter release. Neuron 10 $1185-1196$.

Wilklund L, Toggenburger G, Cuenod M (1982) Aspartate: possible neurotransmitter in cerebellar climbing fibres. Science 216:78-80.

Yamada KA, Rothman SM (1992) Diazoxide blocks glutamate desen-

- sitization and prolongs excitatory postsynaptic currents in rat hippocampal neurons. J Physiol (Lond) 458:409-423.

Yanada KA, Tang C-M (1993) Benzothiadiazides inhibit rapid glutamate receptor desensitization and enhance glutamatergic synaptic currents. J Neurosci 13:3904-3915.

Yawo H, Chuhma N (1993) Preferential inhibition of $\omega$-conotoxinsensitive presynaptic $\mathrm{Ca}^{2+}$ channels by adenosine autoreceptors. Nature 365:256-258. 